\title{
Welcome to the Multiverse: Law, Technology and Humans
}

\author{
Kieran Tranter \\ General Editor, Law, Technology and Humans, Faculty of Law, Queensland University of Technology, Brisbane, Australia
}

The multiverse has invaded popular consciousness from its inception in the realms of theoretical physics. ${ }^{1}$ It is an intriguing concept - this universe is but one of an infinity of universes budding and bubbling together, ${ }^{2}$ and within this multiform reality, the laws and rules of our universe twist and change. Indeed, in science fiction, the 'parallel worlds' trope has a long legacy with countless narratives based on the premise that somewhere in the multiverse are other Earths and other versions of you-each living the consequences of different decisions. ${ }^{3}$

The multiverse theory is a reminder and a warning that there is not a single reality, a single perspective, only one way to see and know the world. The assertion of a multiverse, gleaned from attempts to synthesise the subatomic of the quantum with the exceptionally large (physically and conceptually) of galaxies and gravity, ${ }^{4}$ is an injunction to wonder, speculate and confidently see the world anew.

But why am I invoking the multiverse in introducing the journal Law, Technology and Humans? It is because at this moment, when global culture is becoming highly aware of technology and technologically driven change (often described with dynamic modifiers such as innovation or disruption), there has been a diminishing? In this technologically infused society, culture, economy and even humanity are often ignored. A metanarrative of technology as a source of anxiety or hope for the future has become entrenched in society, and technology is commonly presented as an asocial alien force that comes to the world to cause change. In this narrative, law, regulation, ethics and forms of human normative ordering are required to channel technological change towards the common good. ${ }^{5}$ Despite the traditions within the philosophy of technology, palaeoanthropology, and science and technology that centre technology as intimate and internal to humanity the mainstream metanarrative disregards the complexity of the relationship between technology and humans. Therefore, legal thinking about technology-the emerging field of "technology law' - tends towards speculative, doctrinal analyses that are surprisingly empty. There is an emptiness regarding values and the future good that technology should be channelled towards by law, and regulation and ethics remain abstract or under-articulated. There is a reluctance to commit to substantive values beyond the legacy of the positivist's traditional concern with 'rule of law', coverage and the elimination of ambiguities and anomalies. Often the issue of values is deferred to an amorphous 'society' or 'policymakers' or an imagined human collective ('we') who decide the end towards which technology must be channelled. ${ }^{7}$ Human rights instruments are sometimes invocated as unchallenged trumps but without an awareness of the contestation and critique of rights and rights discourse.

\footnotetext{
${ }^{1}$ Wolfe, "Surfing the Multiverse"; Kukkonen, "Navigating Infinite Earths."

${ }^{2}$ Carr, "Universe or Multiverse?"

${ }^{3}$ Csicsery-Ronay, The Seven Beauties of Science Fiction, 81-2.

${ }^{4}$ Wallace, The Emergent Multiverse.

${ }^{5}$ Tribe, Channeling Technology through Law.

${ }^{6}$ Guihot, "Coherence in Technology Law."

${ }^{7}$ Tranter, "The Law and Technology Enterprise."
}

This work is licensed under a Creative Commons Attribution 4.0 International Licence. As an open access journal, articles are free to use with proper attribution. ISSN: 2652-4074 (Online) 
There is a further emptiness in the substance of technology law. The guiding metanarrative of alien technology affecting the future predisposes towards a vacuum. The direction of analysis is often that the imagined, speculated technological change opens up a lawless space. In other words, there is a gap in the law that needs to be filled, and it is here that the reluctance to articulate values becomes obvious. Further, the analysis and the deferral of values has a distinctly 'procedural' and 'technical' sensibility, attracting the attention of waggish critics who observe the irony that technology law attempts to structure technological futures through a distinct manifestation of teché. ${ }^{8}$

Law, Technology and Humans aims for something different from the mainstream of technology law scholarship. Rather than repeating analysis born from the dominant narrative, it boldly presents itself as a portal to the multiverse of stories and methods through which to understand, dream, critique, build and live well in the technological present as it, with every planetary rotation, moves towards the technological future.

That Law, Technology and Humans is creating a location for a multiverse of scholarship on technology law can be seen in the banner image. When most technology law scholarship is visualised, a very particular aesthetic is imagined and imaged; it is often like the image in Figure 1.

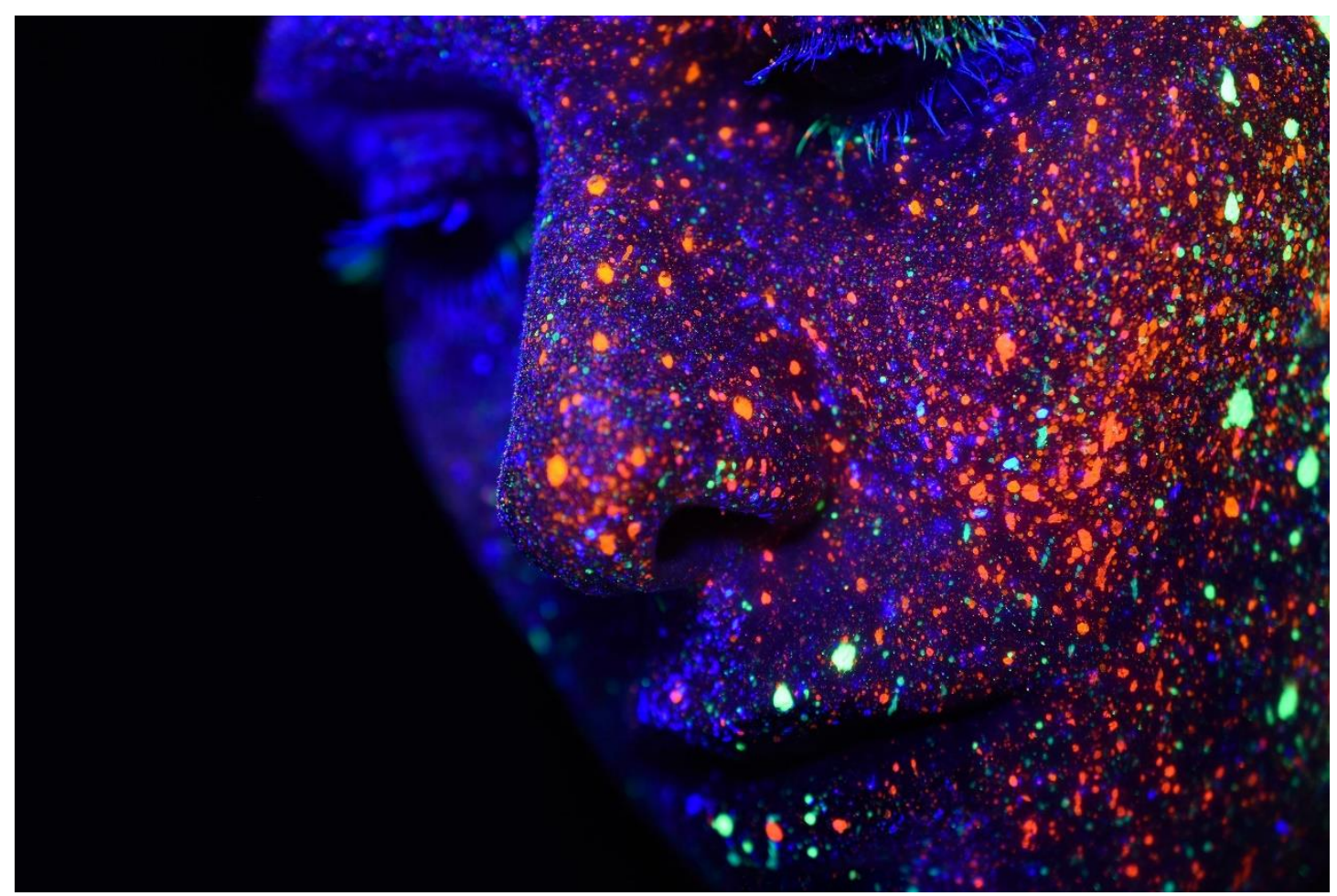

Figure 1: Photo by $\underline{\text { h heyerlein }}$ on Unsplash

There is a suggestion of high-tech digitality in the LED pixels shining through the figure's face in figure 1 . It hints of a cybernetic fusion of human and informatics within a smooth science-fiction future. There is a next stage of humanity implied by this physiognomy floating in the blackness of the void. It is a face that is disconnected, without context, and if the eyes are the windows to the soul, it is a soulless image. It reflects the drive within technology law and its promotion to wrap itself in the aesthetics of the future, disregarding any sense of depth or location. The image is striking, but there is an uncanny emptiness. It is in reaction to the tendency to represent technology law in this way that the banner image for Law, Technology and Humans (Figure 2) is offered.

\footnotetext{
${ }^{8}$ Tranter, Living in Technical Legality, 32-42.
} 


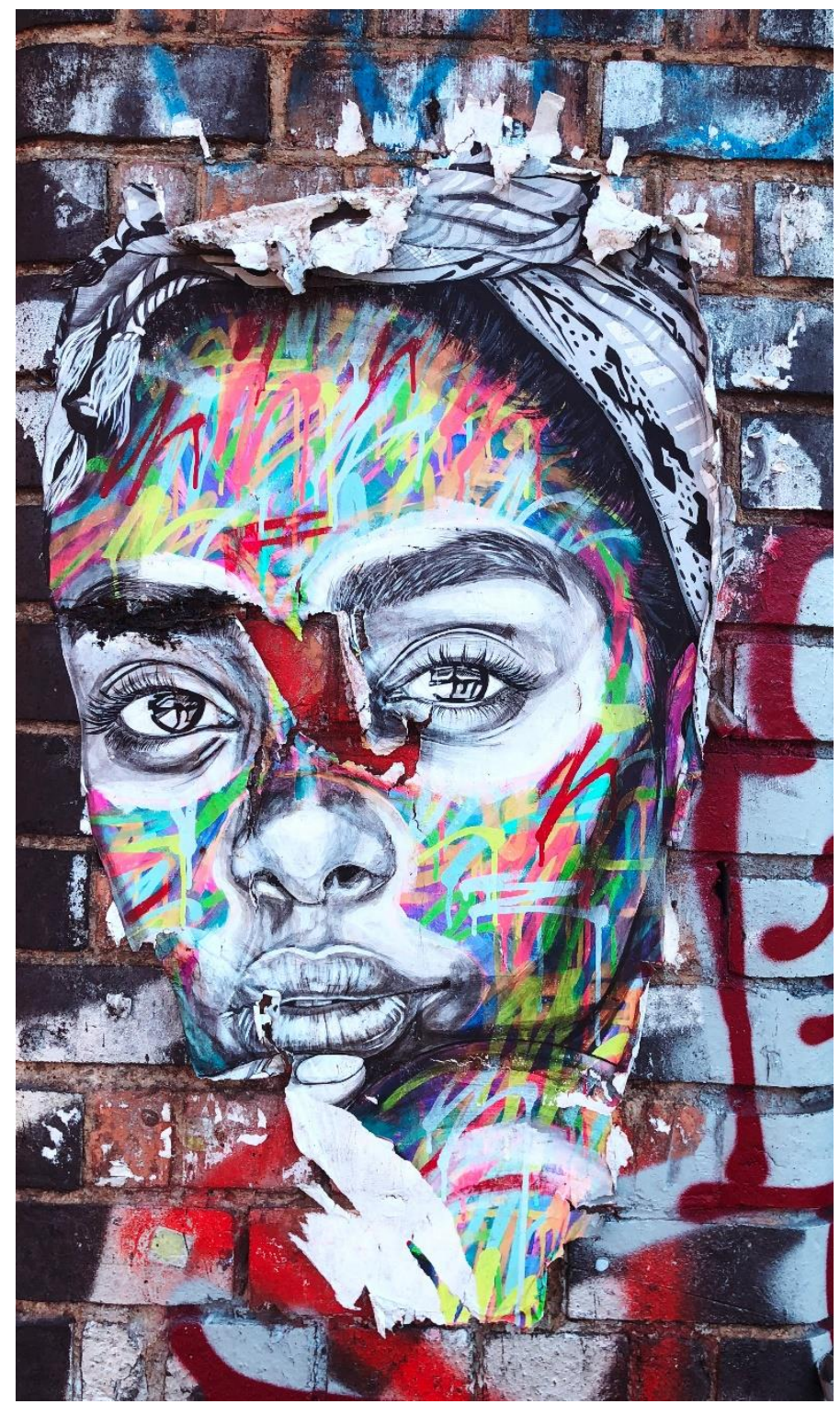

Figure 2: Banner image for Law, Technology and Humans - photograph by Jon Tyson

The banner image does not project the expected aesthetics of technology law. In contrast to figure 1, it has substance-implied by brick and the piercing gaze of eyes. But how does this image, seemingly so removed from the expected aesthetics, depict the desired multiverse of Law, Technology and Human? Indeed, how are the three keywords of the title denoted by this image?

There is law in this image, although it is not the usual legal iconography of books and courts nor the paraphernalia of institutional justice. Law is immediately suggested by action. This image is public art-graffiti-there is in it an unknown quality as to its legality. Is this image illegal - a trespass on private property by paint and creativity? Or is it legal, protected by laws and regulations on the preservation of public art as cultural heritage or as a right to free expression? Its liminal legality suggests not only the core tools of modern law-property, rights, policing and regulation — but also rival legalities to the sovereignty of modern law — the spontaneous 'laws' of diverse human communities.

Technology is front and centre; although, it is not the smooth, LED-lit, futurist aesthetic of figure 1. Here technology has become the everyday - unremarkable and unnoticed. It is the technology of bricks and the suggestion of a New York brownstone, technological assemblages that have given rise to intense global urbanisation. In its graffiti aesthetic, massproduced aerosol spray-paint is denoted - a highly problematic technology not only in its public art applications and its liminal demarcation of subcultures - but also in its contribution to urban pollution and, by extension, to climate change. The image 
reminds us that technologies lose their shiny newness and become commonplace. Yet there are unpredictable consequences, and they are deployed by humans to make meaning in surprising ways.

This brings us to the dominant projection from the image. The portrait is of a woman of colour. She is emerging through the brickwork. Her striking eyes are watching, and a reflective finger is gently resting on her chin. She is an alternative to George Orwell's Big Brother. She is watching, thinking, possibly judging, but without the technological horror of the authoritarian panopticon and with suggestions of a headscarf, she is not the man of privilege and power that is often invoked when law and technology are discussed. Yet she is not passive; there is a sense of purpose in her watching, thinking and judging. She is colourful. She is composed of law and technology, yet her humanity is evident. She urges contributors to the journal to see, reflect, think and judge the ways that law and technology are making and remaking humans and their world—-to bring a sense of wonder and diversity that is inspired by the imagined possibilities of the multiverse.

This is what I hope readers will find in the articles featured in this foundation issue. It is in two parts. The first is a symposium: 'Automation and Disruption in the Legal Profession'. The impact of the digital is a topic of considerable currency and debate in the legal academy and profession; alarmist claims of the end of lawyers are matched by assertions of innovation and opportunities. However, the articles curated for this symposium do not reiterate these manifestations of the technology metanarrative. Rather, there is a quest for knowledge and understanding. Lisa Webley, John Flood, Julian Webb, Francesca Bartlett, Kate Galloway and Kieran Tranter open the symposium with a nuanced attempt to navigate through the manifestations of the technology metanarratives with their imaginings of the future of the legal profession. Expressing dissatisfaction with the three stories - the endurance of the true professional, the disruptive innovator of NewLaw and the death of the legal profession-within the ambit of this discourse, they chart an informed alternative-the adaptive professional-which could project a more sustainable and hopeful future for lawyers. In the follow-up article, Kate Galloway, Julian Webb, Francesca Bartlett, John Flood and Lisa Webley take this vision of the adaptive professional and develop the blueprint for a new curriculum and approach to learning within the legal academy. Margaret Thornton's article marks a change in method. She writes up a study of the human present of NewLaw practice in Australia-how the decomposition to 'gigs', a desire for flexibility, and gender and generational divides are presenting a much more complicated reality than that of the wider discourse. This empirical approach is also taken by Stebin Sam and Ashley Pearson. They report on the diffusion and utilisation of technologies in the community legal sector in Queensland, Australia. Their study finds that expectations of technological backwaters are unfounded. While these centres are not necessarily embracing shining, headline-grabbing technologies such as AI and blockchain, they use an informed approach to innovation-driven by client need and resource limitations. The final article in the symposium does look to a headline-grabbing technology-AI. Felicity Bell and Justine Rogers do not use a doctrinal examination of the law of lawyering's adaptability to imagine the use of AI by legal professionals. Instead, drawing from social psychology, they build a more sophisticated model of a lived, experiential ethics for the lawyer/AI hybrid.

The second part of this issue is dedicated to general articles. Kate Wilkinson Cross places law and technology with the Anthropocene. She identifies, through a structured analysis of international biodiversity instruments, a propensity to see technological innovation as saviour, which has the effect of discouraging reflection on the essential social and economic factors behind biodiversity loss. Hui Chia looks towards the deployment of robo-advisors in the financial services market. Faced with the well-established problems with human advisors, she recommends 'explainability' and transparency of the robot 'personality' to increase trust. Finally, Sarah Hook and Sandy Noakes undertake a cartography of Australian employment tribunals and courts, attempting to chart the context wherein social media use by employees provides grounds for their dismissal.

To commit to a journal, especially an open access, Creative Commons journal, takes courage in a diminishing world of academic publishing in which metrics are stifling thought and creativity. Therefore, I would particularly like to thank Professor John Humphrey, former Executive Dean, Professor Belinda Carpenter, Associate Dean, Research, Professor Afshin AkhtarKhavari, Director of Research and Associate Professor Judith McNamara, Head of the School of Law - all from the Faculty of Law, Queensland University of Technology; they had the courage to support a new journal and the fortitude to support the multiverse vision for Law, Technology and Humans. Additionally, I sincerely thank the members of the International Editorial Board who had the courage to support the formation and operation of the journal. I also need to thank Tracy Creagh, newly appointed Journal Manager with the Faculty of Law, who has taken our journal from its conception as half a page of scribbled lines to the polished professional publication that is today. 


\section{Bibliography}

Carr, Bernard and George Ellis. "Universe or Multiverse?” Astronomy and Geophysics 49, no 2 (2008): 2.29-2.33. https://doi.org/10.1111/j.1468-4004.2008.49229.x

Csicsery-Ronay, Istvan. The Seven Beauties of Science Fiction. Middletown, Connecticut: Wesleyan University Press, 2008.

Guihot, Michael. "Coherence in Technology Law." Law, Innovation and Technology 11, no 2 (2019): 311-42. https://doi.org/10.1080/17579961.2019.1665792

Kukkonen, Karin. "Navigating Infinite Earths: Readers, Mental Models, and the Multiverse of Superhero Comics." Storyworlds: A Journal of Narrative Studies 2, no 1 (2010): 39-58. DOI: 10.1353/stw.0.0009

Tranter, Kieran. "The Law and Technology Enterprise: Uncovering the Template to Legal Scholarship on Technology." Law, Innovation and Technology 3, no 1 (2011): 31-83. https://doi.org/10.5235/175799611796399830

-Living in Technical Legality: Science Fiction and Law as Technology. Edinburgh: University of Edinburgh Press, 2018.

Tribe, Laurence H. Channeling Technology through Law. Chicago: The Bracton Press, 1973.

Wallace, David. The Emergent Multiverse: Quantum Theory According to the Everett Interpretation. Oxford: Oxford University Press, 2012.

Wolfe, Gary. "Surfing the Multiverse.” Nature 448, no 7149 (2007): 25-26. https://doi.org/10.1038/448025a 